\title{
Clinicopathological Significance of Nerves in Esophageal Cancer
}

\author{
Nathan Griffin, ${ }^{* \dagger}$ Christopher W. Rowe, ${ }^{\dagger \dagger}$ Fangfang Gao, ${ }^{* \dagger}$ Phillip Jobling, ${ }^{* \dagger}$ Vanessa Wills, ${ }^{\ddagger \S}$ Marjorie M. Walker, ${ }^{\dagger \dagger}$ \\ Sam Faulkner, ${ }^{* \dagger}$ and Hubert Hondermarck ${ }^{* \dagger}$
}

\begin{abstract}
From the Faculty of Health and Medicine, * School of Biomedical Sciences and Pharmacy, and the Faculty of Health and Medicine, ${ }^{\ddagger}$ School of Medicine and Public Health, University of Newcastle, Callaghan, the Hunter Medical Research Institute, ${ }^{\dagger}$ University of Newcastle, New Lambton, and the Department of Surgery, ${ }^{\S}$ John Hunter Hospital, Newcastle, New South Wales, Australia
\end{abstract}

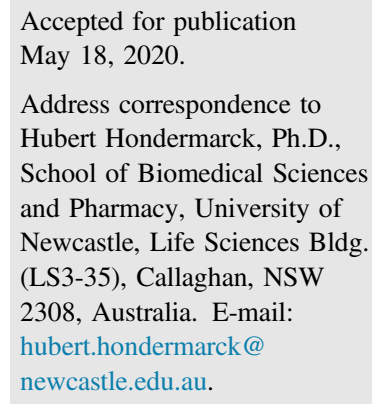

\begin{abstract}
Nerves are emerging promoters of cancer progression, but the innervation of esophageal cancer and its clinicopathologic significance remain unclear. In this study, nerves were analyzed by immunohistochemistry in a cohort of 260 esophageal cancers, including 40 matched lymph node metastases and 137 normal adjacent esophageal tissues. Nerves were detected in $38 \%$ of esophageal cancers and were more associated with squamous cell carcinomas $(P=0.04)$. The surrounding or invasion of nerves by cancer cells (perineural invasion) was detected in $12 \%$ of esophageal cancers and was associated with reduced survival $(P=0.04)$. Nerves were found to express the following receptors for nerve growth factor (NGF): neurotrophic receptor tyrosine kinase 1 and nerve growth factor receptor. An association was suggested between high production of NGF by cancer cells and the presence of nerves $(P=0.02)$. In vitro, NGF production in esophageal cancer cells was shown by Western blot, and esophageal cancer cells were able to induce neurite outgrowth in the PC12 neuronal cells. The neurotrophic activity of esophageal cancer cells was inhibited by anti-NGF blocking antibodies. Together, these data suggest that innervation is a feature in esophageal cancers that may be driven by cancer cellreleased NGF. (Am J Pathol 2020, 190: 1921-1930; https://doi.org/10.1016/j.ajpath.2020.05.012)
\end{abstract}

Nerves in the microenvironment of solid tumors now are recognized as drivers of cancer progression. ${ }^{1}$ In prostate, ${ }^{2}$ gastric, ${ }^{3,4}$ skin, ${ }^{5}$ pancreatic, ${ }^{6,7}$ and breast $^{8}$ cancers, tumor innervation is associated with cancer aggressiveness and denervation significantly inhibits cancer progression. These pioneering studies developed the concept of nerve dependence in cancer, where molecular crosstalk between cancer cells and nerves participate in the initiation and progression of the disease. ${ }^{9}$ For example, in pancreatic cancer, sympathetic nerves release noradrenaline, stimulating cancer cell proliferation through $\beta$ receptors, ${ }^{7}$ and in gastric cancer, cholinergic nerves release acetylcholine, which stimulates cancer growth via muscarinic receptors. ${ }^{4}$ In addition, in prostate cancer, noradrenalin released from sympathetic nerves is a potent stimulator of angiogenesis. ${ }^{10}$ Interestingly, a feed-forward loop exists wherein the stimulation of tumors via locally released neurotransmitters induces the release of nerve growth factor (NGF) from cancer cells, further promoting tumor innervation. $4,7,11$
In esophageal cancer, the presence and potential impact of nerves in the tumor microenvironment is unclear. In fact, knowledge of the specific innervation of the normal human esophageal mucosa is limited. Evidence suggests that the upper esophagus is more sensitive to mechanical and chemical stimuli than the lower esophagus. ${ }^{12,13}$ In addition, it has been reported that afferent nerves in the mucosa of the proximal esophagus are located more superficially (cell layers closest to the lumen) than the distal esophagus. ${ }^{14}$ In esophageal cancer, one early investigation has provided evidence for the presence of peptidergic nerves in primary human esophageal carcinomas. ${ }^{15}$ The expression of NGF by esophageal cancer cells is associated with poor prognosis,

Supported by Hunter New England Local Health District project grant G1601109 (H.H.).

S.F. and H.H. contributed equally to this work.

Disclosures: H.H. is on the Scientific Advisory Board of Cygnal Therapeutics. 
however, it is not known if NGF also might contribute to esophageal cancer innervation. ${ }^{16}$

To date, the majority of investigations into nerve-cancer interactions have focused on the prognostic value of perineural invasion (PNI), a process whereby cancer cells surround and invade nerves, using the pathways for dissemination and metastasis. ${ }^{17-20}$ PNI generally is thought to be a predictor of recurrence and poor survival in a variety of different malignancies such as prostate, pancreatic, and gastric cancers. ${ }^{21-23}$ In esophageal cancer, reports on the prognostic role of PNI are conflicting. Several reports have suggested PNI as an independent prognostic factor of poor outcomes and recommended PNI to be used for therapy stratification. ${ }^{19,20}$ However, other data have suggested that PNI is not associated significantly with cancer-specific survival and does not possess independent prognostic value in esophageal cancer. ${ }^{24,25}$

In the present study, the clinicopathologic significance of nerves in the tumor microenvironment of esophageal cancer was investigated. Nerves were detected in a significant proportion of esophageal cancers and were associated more specifically with squamous cell carcinoma histologic subtype. An association between high production of NGF by cancer cells and the presence of nerves was observed. Furthermore, in vitro, squamous esophageal cancer cells induced neurite outgrowth via the release of NGF, thus pointing to a possible NGF-driven nerve infiltration in esophageal cancer.

\section{Materials and Methods}

\section{Esophageal Tissue Samples}

High-density tissue microarrays (TMAs) were obtained from Biomax, Inc. (Derwood, MD). The TMAs used (catalog numbers ES804, ES2001a, and HEso-Squ180Sur-03) included a total of 303 esophageal cancer tissues (of adenocarcinoma and squamous subtypes), 40 matched lymph node metastases, and 137 normal adjacent tissues. The following clinicopathologic information was available: patient age and sex, histologic subtype, tumor size, grade, lymph node status, and survival status. Biomax, Inc., quality controls are described as follows. Each single tissue spot on every array slide was examined individually by certified pathologists according to World Health Organization published standardizations of diagnosis, classification, and pathologic grade. ${ }^{26}$ Each specimen collected was consented to by both the hospital and the individual. Discrete legal consent was obtained and the rights to hold research uses for any purpose or further commercialized uses were waived. The study was approved by the Human Research Ethics Committee of the University of Newcastle (approval H-2012-0063).

\section{Immunohistochemistry}

Immunohistochemistry was performed as previously described. ${ }^{27}$ After deparaffinization and rehydration of the TMA slides following standard procedures, heat-induced epitope retrieval was performed in a low-pH, citrate-based, antigen-unmasking solution (catalog number H-3300; Vector Laboratories, Burlingame, CA) using a decloaking chamber (Biocare, West Midlands, United Kingdom) at $95^{\circ} \mathrm{C}$ for 20 minutes. Immunohistochemistry then was performed using an ImmPRESSTM horseradish peroxidase IgG (peroxidase) Polymer Detection Kit (Vector Laboratories), as per the manufacturer's recommendations. Briefly, after inactivation of endogenous peroxidases with $0.3 \% \mathrm{H}_{2} \mathrm{O}_{2}$, and blocking with $2.5 \%$ horse serum, tissues were probed with primary antibodies at the following specified dilutions: anti-ubiquitin C-terminal hydrolase L1 (UCHL1 1/500 dilution (ab15503; Abcam, Cambridge, UK), anti-NGF 1/200 dilution (ab52918; Abcam), anti-neurotrophic receptor tyrosine kinase 1 (NTRK1, also know as TRKA) 1/200 dilution (2510, 12G8; Cell Signaling Technology, Danvers MA), anti-nerve growth factor receptor (NGFR, also known as p75NTR) 1/500 dilution (4201, D8A8; Cell Signaling Technology). The signal was amplified with horseradish peroxidase-conjugated antibodies 711-035-152 anti-rabbit IgG (Jackson Immunoresearch, West Grove, PA) 1/400 in saturating buffer for 2 hours at $37^{\circ} \mathrm{C}$ and shown with the diaminobenzidine peroxidase (horseradish peroxidase) Substrate Kit (SK-4100; Vector Laboratories). Finally, TMA slides were counterstained with hematoxylin (Gill's formulation; Vector Laboratories), dehydrated, and cleared in xylene before mounting in Ultramount \#4 mounting media (Thermo Fisher Scientific, Victoria, Australia). Negative controls, using isotype control antibodies (rabbit IgG isotype control $0.8 \mu \mathrm{g} / \mathrm{mL}, 3900$; Cell Signaling Technology), are shown in Supplemental Figure S1.

\section{Double Immunostaining}

Double immunostaining was performed using the ImmPRESS Duet Double Staining Polymer Kit (MP-7714; Vector Laboratories) as per the manufacturer's recommendations. Briefly, after deparaffinization, rehydration, inactivation of endogenous peroxidases with $\mathrm{H}_{2} \mathrm{O}_{2}$, and blocking with $2.5 \%$ horse serum, the mouse ubiquitin C-terminal hydrolase L1 (UCHL1) antibody (ab8189; Abcam) and rabbit NGF antibody (ab52918; Abcam) were combined and applied to the sections. ImmPRESS Duet Reagent (horseradish peroxidase horse anti-mouse IgG/AP horse anti-rabbit IgG; Vector Laboratories) was applied for 20 minutes followed by ImmPACT diaminobenzidine $\mathrm{EqV}$ substrate for 2 minutes. Slides then were washed in buffer before ImmPACT Vector Red substrate was applied for 2 minutes. Finally, tissues slides were washed, counterstained with hematoxylin QS nuclear counterstain (H-3404; Vector Laboratories), dehydrated, and cleared in xylene before mounting in Ultramount \#4 mounting media (Thermo Fisher Scientific).

\section{Digital Quantification of Immunohistochemistry Staining Intensities}

Quantification of NGF staining intensities was performed as previously described ${ }^{27}$ using the Aperio AT2 scanner (Leica 
Biosystems, Victoria, Australia) and the Halo image analysis platform (Indica Labs, Albuquerque, NM) under the supervision of a pathologist (M.M.W.). Pixel intensity values were used to determine the $\mathrm{h}$-scores for each core (index was calculated as the sum of $3 \times$ the percentage of pixels with strong staining $+2 \times$ the percentage of pixels with intermediate staining $+1 \times$ the percentage of pixels with weak staining). NGF intensity was classified as low (h-score, $<25$ ), medium (h-score, $\geq 25$ to $<50$ ), and high (h-score, $\geq 50$ ), with the medium category approximately equivalent to the interquartile range of the data.

\section{Identification of Nerves and Perineural Invasion in Esophageal Cancer}

The presence or absence of nerve fibers was recorded for each individual tumor sample under the supervision of a pathologist (M.M.W.). Nerve positivity was defined as the presence of individual nerve fibers within the tumor core. Nerves were identified based on histologic context and positive reaction to anti-UCHL1 antibody. Perineural invasion was defined using the current prevailing definition: the presence of a nerve trunk (large nerve composed of many individual nerve fibers) with cancer cells surrounding a minimum of $33 \%$ of the circumference of the nerve or tumor cells within any three layers of the nerve sheath. ${ }^{28}$

\section{Statistical Analysis}

The presence of nerve fibers and PNI in primary tumors (considered as binary variables of absent or present) were each compared with clinicopathologic parameters. Separate logistic regression models were constructed for the presence of nerves, and the presence of perineural invasion (as the dichotomized dependent variable), including model variables of age, sex, tumor size, and tumor grade. Histologic subtype was not included owing to collinearity. Survival data were used to construct Kaplan-Meier survival curves, stratified by the presence or absence of nerves (or PNI). Survival data then were used to determine separate Cox proportional hazard ratios, both unadjusted; and adjusting for potential confounders of age, sex, tumor grade, tumor size, and lymph node status. NGF h-scores were considered both as a continuous, normally distributed variable; and in categories of intensity described above (Digital Quantification of Immunohistochemistry Staining Intensities) and assessed using unpaired t-tests and the $\chi^{2}$ test, respectively. Distribution was assessed using histograms and q-q plots. Analyses were performed using Stata v 14.2 (StataCorp, College Station, TX).

\section{Cell Culture}

Squamous esophageal cancer cell lines KYSE30 and KYSE70 were purchased from the European Collection of Authenticated Cell Cultures. The KYSE30 cell line was maintained in RPMI-1640 and Ham's F-12 Nutrient Mix (1:1) (11765054; Thermo Fisher Scientific), supplemented with $2 \%(\mathrm{v} / \mathrm{v})$ fetal calf serum (JRH Bio-sciences, Lenexa, $\mathrm{KS}$ ) and $2 \mathrm{mmol} / \mathrm{L} \mathrm{L}$-glutamine in a humidified incubator at $37^{\circ} \mathrm{C}$ with $5 \%(\mathrm{v} / \mathrm{v}) \mathrm{CO}_{2}$. The KYSE70 cell line was maintained in RPMI-1640 with $10 \%$ (v/v) fetal calf serum (JRH Biosciences). Routine Mycoplasma testing was performed using the MycoAlert Mycoplasma Detection Kit (LT07-118; Lonza, Basel, Switzerland). Cells were not maintained in culture for longer than 3 months to ensure the passage number remained fit for purpose.

\section{Protein Extraction and Western Blot}

Subconfluent esophageal cancer cell monolayers were lysed with $1 \% \mathrm{NP} 40$ lysis buffer $(50 \mathrm{mmol} / \mathrm{L}$ Tris- $\mathrm{HCl}, 150$ $\mathrm{mmol} / \mathrm{L} \mathrm{NaCl}, 1 \% \mathrm{NP} 40, \mathrm{pH} 8.0$ ) that contained complete EDTA-free protease inhibitor cocktail (Roche, Mannheim, Germany). Insoluble proteins were removed by centrifugation at $15 \times 10^{3} \times g$ for 10 minutes $\left(\right.$ at $4^{\circ} \mathrm{C}$ ), and the total protein concentration was determined using the microBCA kit (Pierce Biotechnology, Rockford, IL) per the manufacturer's instructions. A total of $24 \mu \mathrm{g}$ protein lysate was separated by SDS-PAGE with $12 \%$ resolving gel and then transferred to $0.4-\mu \mathrm{m}$ pore nitrocellulose membranes (Amersham, GE Healthcare Life Sciences, Pittsburgh, PA) using a wet transblotter (BioRad, Gladesville, NSW, Australia). Blots were blocked with blocking buffer (LI-COR Biosciences, Lincoln, NE) for 1 hour at room temperature and then probed with anti-NGF antibody (sc-548; Santa Cruz Biotechnology, Dallas, TX) at a dilution of 1:200, diluted in the blocking buffer. $\beta$-actin detection (1/5000 dilution, A2066; Sigma-Aldrich, St. Louis, MO) was used as the equal loading control. After washing with phosphate-buffered saline that contained $0.1 \%$ Tween 20 , membranes were probed with goat anti-rabbit 800 continuous wave-labeled secondary antisera, and then washes were repeated after labeling. Western blot was imaged using the LI-COR Odyssey infrared imaging system (LI-COR).

\section{Neurite Outgrowth Assay}

The neurotrophic ability of esophageal cancer cells was tested in co-culture experiments with the neuronal-like PC12 cells and neurite outgrowth was measured. PC12 cells are used extensively for studying neurite outgrowth. ${ }^{29}$ For co-culture experiments, PC12 cells $(50,000$ cells in 1 $\mathrm{mL}$ ) were seeded on bottom wells of 12-well Transwell plates (Corning, Corning, NY) coated with rat-tail collagen I (Invitrogen, Carlsbad, CA). After 24 hours, they were serum-starved in Dulbecco's modified Eagle's medium containing $1 \%$ horse serum. Esophageal cancer cells were grown in Transwell inserts (diameter, $12.0 \mathrm{~mm}$; pores, $0.4 \mu \mathrm{m}$; Corning). Differentiation of PC12 cells was allowed for 3 days, with or without anti-NGF mouse monoclonal 

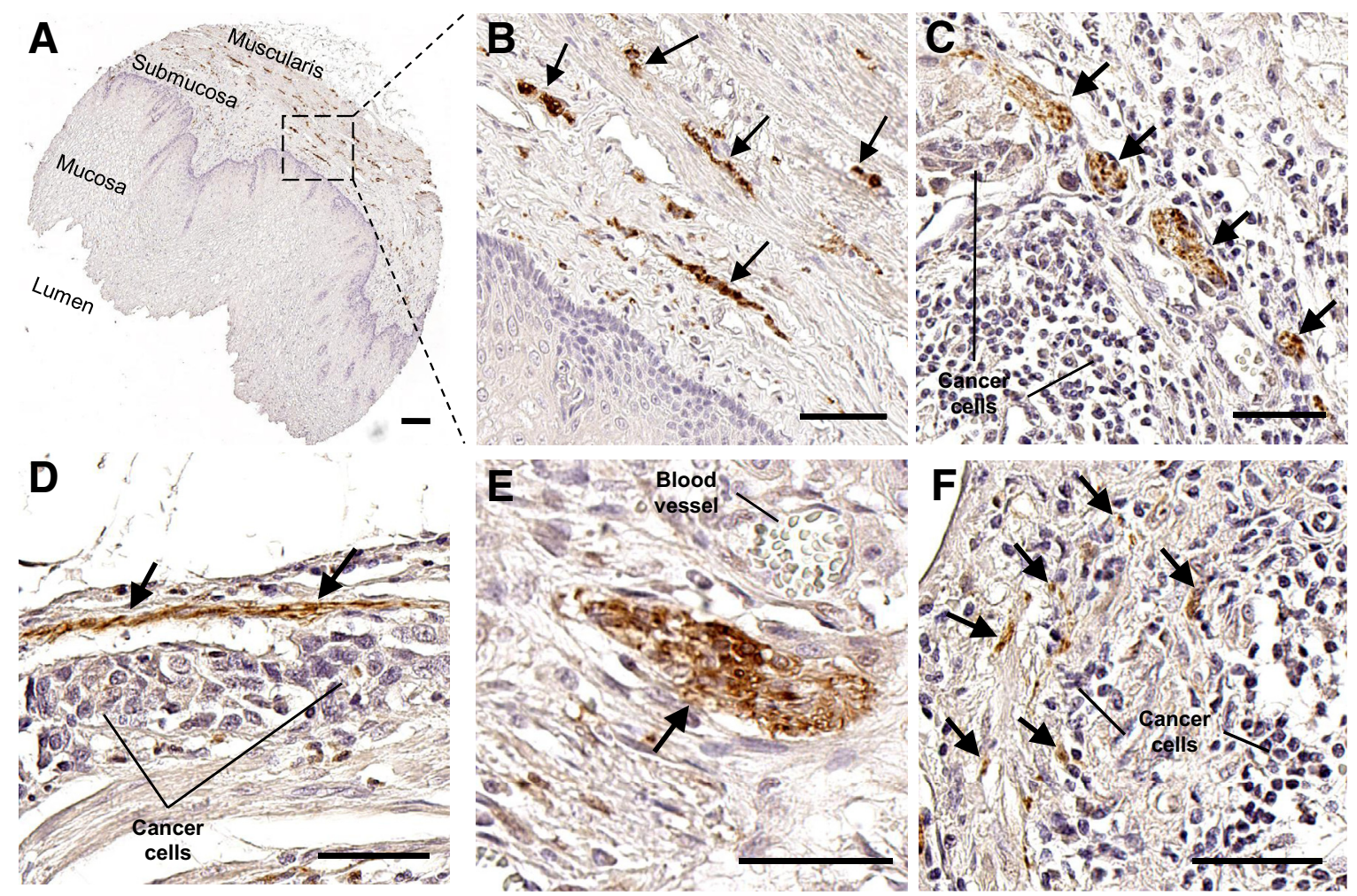

Figure 1 Nerves in the microenvironment of esophageal cancer. A: Low magnification of normal esophagus stained using immunohistochemistry for the pan-neuronal marker ubiquitin C-terminal hydrolase L1 (UCHL1) and counterstained with hematoxylin. In the vast majority of normal esophageal tissues, small nerves are observed in the submucosal and superficial muscularis layers. B-F: Nerves are indicated by arrows. B: Enlargement of nerves in boxed area in A in the submucosal layer of the normal esophagus. C and D: Nerves within esophageal tumors adjacent to cancer cells. E: Large nerve trunk (composed of many individual axons) within the esophageal cancer microenvironment adjacent to a blood vessel. F: Individual axons are observed within the tumor stroma of an esophageal cancer lymph node metastasis. Scale bars: $100 \mu \mathrm{m}$ (A); $50 \mu \mathrm{m}(\mathbf{B}-\mathbf{F})$.

blocking antibody (alm-006; Alomone, Jerusalem, Israel) and neurite elongation was measured. PC12 cells showing neurites of at least twice the size of the cell body were considered as differentiated. Images were captured using a Zeiss Axiovert 200 inverted microscope fitted with an AxioCam HRm digital camera (Zeiss AG, Oberkochen, Germany). The one-way analysis of variance statistical test (GraphPad Prism 5.01; GraphPad Software, San Diego, CA) was used. The protocol described here was repeated utilizing the immortalized dorsal root ganglion neuronal cell line 50B11 (kindly provided by Dr. Ahmet Höke, John Hopkins University, Baltimore, MD) to corroborate findings in PC12 cells.

\section{Results}

Innervation of the Microenvironment in Esophageal Cancers

To investigate the presence of nerves within esophageal tumors, immunohistochemistry against the pan-neuronal marker UCHL1 (alias PGP9.5) was performed. Typical morphologic features corresponding to both nerve trunks (composed of many axons) and isolated individual axons were observed (Figure 1). Nerves were detected in nearly all normal tissues
(96\% of cases) (Table 1), and all were localized in the submucosal and superficial muscularis layers of the esophageal lining (Figure 1, A and B). No nerves were detected in the stratified squamous epithelial layer of the esophagus. In esophageal cancer, nerve trunks were localized throughout the cancer cell mass of both adenocarcinoma and squamous cell carcinoma histologic subtypes. Both individual axons and larger nerve trunks frequently were identified adjacent to malignant epithelial cells (Figure 1, C-F). Nerves often were localized in close proximity to or surrounding blood vessels (Figure 1E). In addition, individual axons also were detected in matched lymph node metastases (Figure 1F). Overall, nerve infiltration within esophageal tumors was observed in $38 \%$ of cancer cases (Table 1). Nerves also were identified in $18 \%$ of lymph node metastases.

Nerves were identified in 95 of $238(40 \%)$ cancers of the squamous subtype, and in 4 of $22(18 \%)$ of the adenocarcinoma subtype. A multivariate logistic regression model was constructed, with the presence or absence of nerves as the dichotomized dependent variable, and model variables of histopathologic subtype, age, and sex. The model with histopathologic subtype alone gave an odds ratio in favor of squamous histopathology of 2.99 (95\% CI, 0.98-9.10; $P=0.045$ ). The full model (with the addition of age and sex) gave an odds ratio of 2.92 (95\% CI, 0.95-8.98). There 
Table 1 Demographic and Disease-Specific Parameters for Included Cases

\begin{tabular}{|c|c|c|}
\hline Parameter & $\begin{array}{l}\text { Benign } \\
\text { esophagus }\end{array}$ & $\begin{array}{l}\text { Esophageal } \\
\text { carcinoma }\end{array}$ \\
\hline$n$ & 137 & 260 \\
\hline Mean age, y (SD) & $62(11)$ & $60(10)$ \\
\hline \multicolumn{3}{|l|}{ Sex, $n(\%)$} \\
\hline Female & $30(22)$ & $62(24)$ \\
\hline Male & $107(78)$ & $198(76)$ \\
\hline \multicolumn{3}{|l|}{$\begin{array}{l}\text { Histologic subtype, } \\
n(\%)\end{array}$} \\
\hline Adenocarcinoma & NA & $22(8 \%)$ \\
\hline Squamous & NA & $238(92 \%)$ \\
\hline \multicolumn{3}{|l|}{ Tumor size, $n(\%)$} \\
\hline $\mathrm{T} 1-\mathrm{T} 2$ & NA & $52 / 203 *(26)$ \\
\hline $\mathrm{T} 3-\mathrm{T} 4$ & NA & $151 / 203^{*}(74)$ \\
\hline \multicolumn{3}{|l|}{ Grade, $n(\%)$} \\
\hline 1 & NA & $70 / 248 *(28)$ \\
\hline 2 & NA & $89 / 248 *(36)$ \\
\hline 3 & NA & $89 / 248 *(36)$ \\
\hline \multicolumn{3}{|l|}{$\begin{array}{l}\text { Lymph node } \\
\quad \text { metastases, } n(\%)\end{array}$} \\
\hline Negative & NA & $111 / 210^{*}(53)$ \\
\hline Positive & NA & $99 / 210 *(47)$ \\
\hline $\begin{array}{l}\text { Median survival, } \\
\text { months }\end{array}$ & NA & $\begin{array}{l}21(95 \% \text { CI }, 16-38) \\
(n=92)\end{array}$ \\
\hline $\begin{array}{l}\text { Nerves present on TMA } \\
\text { core, } \%(n)\end{array}$ & $96(131 / 137)$ & $38(99 / 260)$ \\
\hline $\begin{array}{l}\text { Perineural invasion } \\
\text { present, } \%(n)\end{array}$ & NA & $12(31 / 260)$ \\
\hline
\end{tabular}

Immunostaining for the pan-neuronal marker ubiquitin C-terminal hydrolase L1 (UCHL1) was performed on a cohort of esophageal carcinomas and normal adjacent tissues. Each clinical case was classified as negative/ positive for the presence of nerves and for the presence of perineural invasion.

NA, not applicable; TMA, tissue microarray.

*Cases in which data points were unavailable are indicated by the denominator.

was no material change in the parameter estimate in the full model, suggesting no evidence of confounding.

To explore associations between innervation of tumors and clinical and pathologic parameters, multivariate logistic regression models were constructed using the presence or absence of nerves as the dichotomized dependent variable and fitting variables of age, sex, tumor grade, tumor size, and lymph node status (Table 2). An association between nerves and sex was identified in which females were less likely to have tumoral innervation than males (odds ratio, 0.35; 95\% CI, 0.17-0.72; $P=0.004$ ) (Table 2). No association between innervation and other variables was shown. There was no significant change in the parameter estimates when adenocarcinomas were excluded from analysis.

\section{PNI in Esophageal Cancer}

The presence of PNI was observed in $11.9 \%$ of esophageal cancer cases, representing $31.3 \%$ of cases positive for nerve infiltration (Table 1). Cancer cells were found tightly surrounding nerve trunks (Figure 2, A and B), penetrating the perineurium (Figure 2C) and in some cases, completely disrupting the perineural structure (Figure 2D). To investigate the potential association between PNI and clinicopathologic outcomes, esophageal cancer cases were categorized as PNI positive or PNI negative. A logistic regression model then was constructed using the presence of PNI as the dichotomized-dependent variable, and fitting model variable of age, sex, tumor grade, tumor size, and lymph node status. Odds ratios (with 95\% CIs) are presented in Table 2. No associations were found between the investigated parameters and the presence of PNI.

Survival data (available for a subset of cases, $n=92$ ) were used to construct Kaplan-Meier survival curves, stratified by the presence or absence of nerves within the TMA (Figure 2E), or by the presence or absence of PNI (Figure 2F). Separate Cox proportional hazard models were fit-adjusted for the potential confounders of age, sex, tumor grade, tumor size, and lymph node invasion. Although no relationship was identified between the presence of nerves and survival, an association was suggested between the presence of PNI and reduced patient survival. In the base Cox model, the unadjusted hazard ratio for PNI was 2.02 (95\% CI, 0.91-4.46; $P=0.08$ ), however, in the full model, adjusting for potential confounders, the hazard ratio was 2.45 (95\% CI, 1.03-5.84; $P=0.04$ ).

\section{NGF Receptors Are Expressed in Nerves, and Esophageal Cancer Cells Express NGF}

Nerves in the tumor microenvironment of esophageal cancers were found to express the NGF receptors NTRK1 (TRKA) and NGFR (p75NTR) in serial sections (Figure 3). The pan-neuronal marker UCHL1 was used to immunolabel nerves (Figure 3A). Some axons in the nerve trunks were

Table 2 Association between the Presence of Nerves and the Presence of PNI and their Association with Clinicopathologic Parameters in Esophageal Cancer

\begin{tabular}{lcl}
\hline Parameter & $\begin{array}{l}\text { Presence of nerves, } \\
\text { odds ratio }(95 \% \mathrm{CI})\end{array}$ & $\begin{array}{l}\text { Presence of PNI, } \\
\text { odds ratio }(95 \% \mathrm{CI})\end{array}$ \\
\hline Age & $1.0(0.97-1.03)$ & $0.99(0.95-1.04)$ \\
Female & $0.35(0.17-0.72)^{*}$ & $0.46(0.15-1.42)$ \\
Tumor size & $0.82(0.46-1.44)$ & $1.07(0.45-2.53)$ \\
Grade & $0.81(0.55-1.20)$ & $1.10(0.64-1.89)$ \\
Nodal metastases & $1.23(0.66-2.30)$ & $1.83(0.76-4.46)$ \\
\hline
\end{tabular}

Immunostaining for the pan-neuronal marker ubiquitin C-terminal hydrolase L1 (UCHL1, also known as PGP9.5) was performed on a cohort of esophageal carcinomas and normal adjacent tissues. A logistic regression model was constructed using the presence or absence of nerves, or the presence or absence of PNI as the dichotomized dependent variable. Model variables of age, sex (male $=0$, female $=1$ ), tumor size (I/II versus III/ IV), tumor grade (I versus II/III), and lymph node status (binary) then were applied.

PNI, perineural invasion.

$* P<0.005$. 

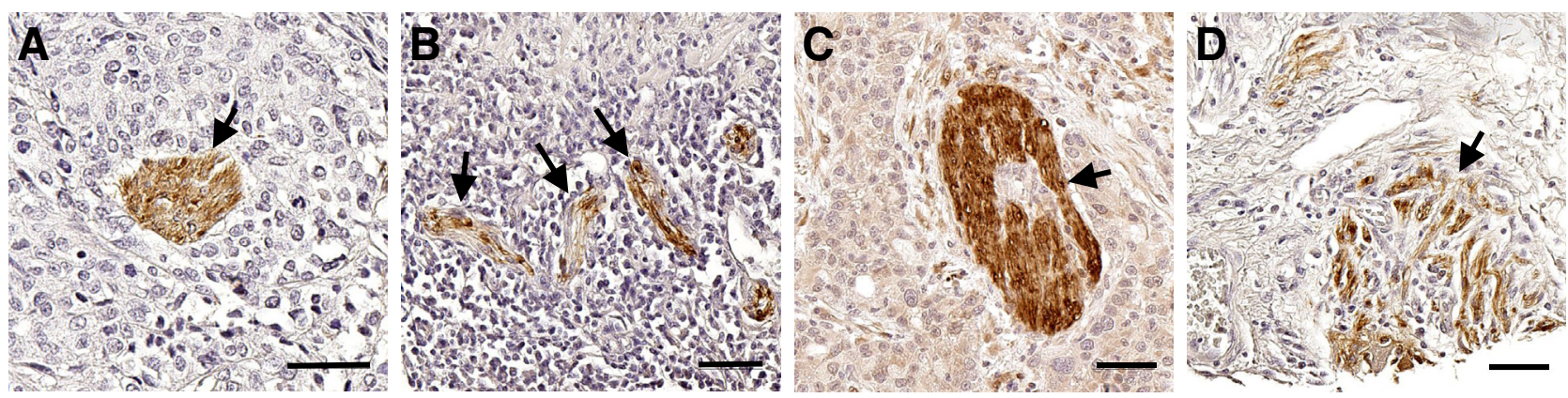

E

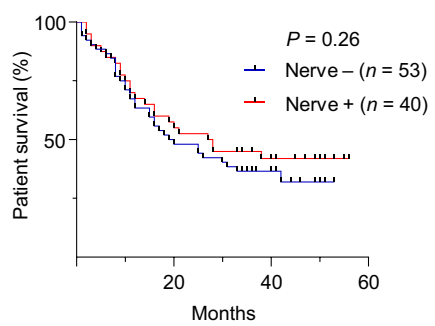

Figure 2 Detection of perineural invasion in esophageal cancer. Immunohistochemistry against the pan-neuronal marker ubiquitin C-terminal hydrolase L1 (UCHL1) was performed on a series of esophageal cancers. A-D: Perineural invasion in cases of esophageal cancer. Nerve trunks are indicated by arrows. A and B: Nerve trunk tightly surrounded by tumor cells. C: Tumor cells invade the nerve trunk, damaging the perineurium. D: Nerve trunk is completely invaded by cancer cells in the perineurium. Cases were identified as positive or negative for the presence of nerves and an association was made with survival. E: Kaplan-Meier survival curve comparing cases that are positive for nerve infiltration versus negative for nerve infiltration. The hazard ratio from a Cox proportional model including variables of age, sex, tumor size, lymph node status, and tumor grade is 0.89 (95\% CI, 0.70-1.59). F: Kaplan-Meier survival curve comparing esophageal cancer cases that were perineural invasion (PNI) positive versus PNI negative. The hazard ratio for perineural invasion from a Cox proportional model including variables of age, sex, tumor size, lymph node status, and tumor grade is 2.45 (95\% CI, 1.03-5.84). Scale bars $=50 \mu \mathrm{m}(\mathbf{A}-\mathbf{D})$.

clearly positive for NTRK1 (Figure 3B) and NGFR (Figure 3C). In contrast, nerves did not express NGF (Figure 3D). However, double immunostaining for NGF and UCHL1 (Figure 4) was performed, and the results showed that both individual nerve fibers (Figure 4, A and B) and larger nerve trunks (Figure 4, C and D) were observed adjacent to or surrounded by cancer cells producing NGF. Nerves rarely were detected in tissues showing low NGF expression (Figure 4E). The expression of NGF in primary esophageal tumors was assessed using immunohistochemistry with digital quantification (h-score) and correlated with the presence of nerves. Nerves were identified in 13\% (3 of 24) of cases with low NGF expression (h-score, <25), compared with $40 \%$ ( 80 of 200) of cases with medium NGF expression (h-score, 25.1 to 50) and 44\% (16 of 36) of cases with high NGF expression (h-score $>50)(P=0.02)$ (Figure 4F). Higher NGF expression (h-scores) continued to be associated with innervation of cancer when considered as a continuous variable $(41.2 \pm 16.8$ versus $36.1 \pm 13.9$; $P=0.01)$.
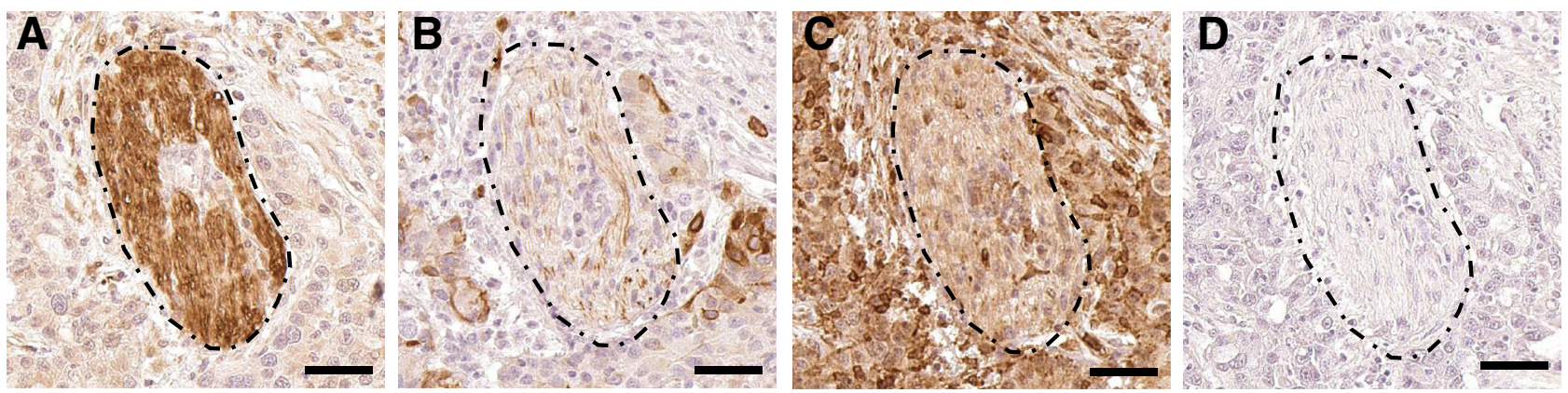

Figure 3 Neurotrophic receptor tyrosine kinase 1 (NTRK1) and nerve growth factor receptor (NGFR) expression in nerves present in esophageal cancer. Immunohistochemical detection of nerve growth factor (NGF) and its receptors in a nerve trunk within the esophageal cancer microenvironment. The dashed lines outline the nerve trunk in each panel. A and D: NTRK1, NGF, and NGFR are detected in serial sections. A: Nerve detected with ubiquitin C-terminal hydrolase L1 (UCHL1) labeling. B: NTRK1 labeling is observed in some axons in a serial section to that presented in A. C: Positive NGFR labeling in the nerve trunk in a serial section to that presented in A. D: No NGF labeling is detected in a serial section to that presented in $\mathbf{A}$. Scale bars $=50 \mu \mathrm{m}$. 

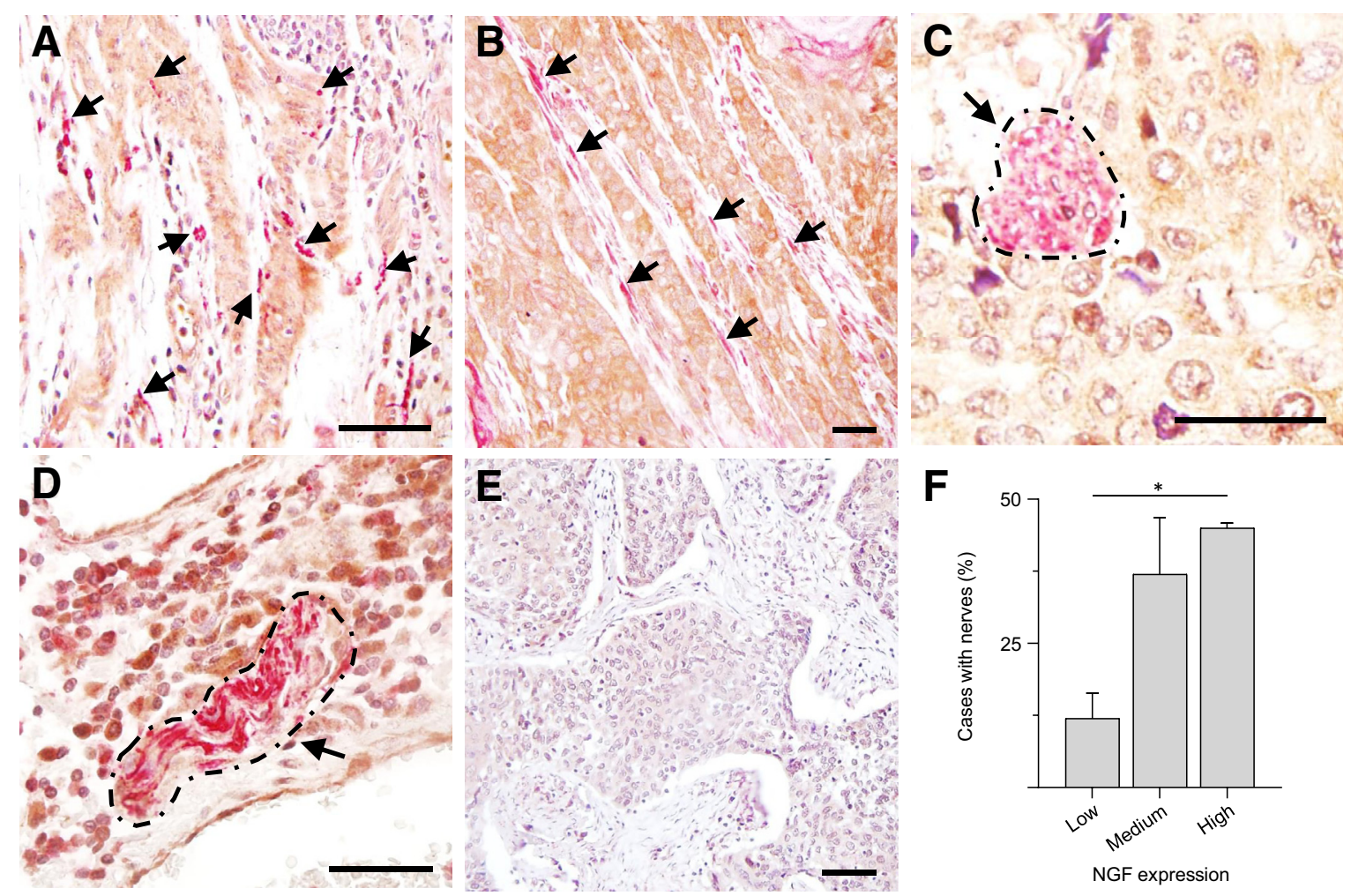

Figure 4 Co-localization between nerves and nerve growth factor (NGF) in esophageal cancer. A-E: Double immunostaining for the neuronal marker ubiquitin C-terminal hydrolase L1 (UCHL1) (magenta) and NGF (brown) was performed on esophageal cancer tissues. Nerves are indicated by arrows. Dashed lines outline the nerve trunk in each panel. A and B: Individual nerve fibers (magenta) are observed within the tumor stroma adjacent to NGF-expressing squamous esophageal cancer cells (brown). C and D: Larger nerve trunks showing perineural invasion (PNI) are surrounded by NGF-expressing squamous esophageal cancer cells. E: Esophageal cancer tissue with low NGF expression. No nerve fibers are detected. F: Distribution of nerve positivity in low, medium, and high NGF-expressing esophageal cancers. Categories of NGF staining are based on the upper and lower quartiles of the data range (low $=$ bottom $25 \%$ of cases, high $=$ upper $25 \%$ of cases). Esophageal cancers presenting with high NGF expression are more likely to be positive for nerve infiltration than those with low NGF expression. Error bars represent the standard error. The $\chi^{2}$ test was used. ${ }^{\star} P<0.05$. Scale bars $=50 \mu \mathrm{m}(\mathbf{A}-\mathbf{E})$.

Importantly, drawing conclusions from TMAs is somewhat conditional on true representation of the tumor in each punch biopsy of the large block, and double staining has allowed the validation of the true absence of the nerves in the tumor in negative cases. A total of 197 of the 397 cases of normal esophageal tissue and esophageal cancer tissue (49.6\%) were investigated in double staining. All positive and negative cases were confirmed, representing $100 \%$ correlation.

\section{Esophageal Cancer Cells Can Induce Neuronal Outgrowth through NGF Secretion}

The ability of esophageal cancer cells to stimulate neuronal outgrowth (neurotrophic activity) was investigated in vitro. First, the expression of NGF in the esophageal cancer cell lines KYSE30 and KYSE70 was confirmed by Western blot (Figure 5A). Transwell co-cultures between esophageal cancer cells and the neuronal PC12 cells were performed and neurite outgrowth of PC12 cells was measured as a percentage of cells with elongated neurites (Figure 5, B-D). KYSE30 and KYSE70 cell lines induced neurite outgrowth in PC12 cells and representative images are shown (Figure 5D). The involvement of NGF in esophageal cancer cell-induced neurite outgrowth was determined by the use of blocking antibodies against NGF (Figure 5, C and D). Anti-NGF antibodies reduced esophageal cancer cell-induced neurite outgrowth by $32 \%$ in KYSE30 $(P<0.0001)$ and by $19 \%$ in $\mathrm{KYSE70}(P=0.0013)$ (Figure 5C). The NGF-mediated neurotrophic ability of esophageal cancer cells was confirmed using the 50B11 cell line (Supplemental Figure S2). The 50B11 cells are derived from dorsal root ganglia and are responsive to NGF. ${ }^{30}$ Both KYSE30 and KYSE70 stimulated axonogenesis in 50B11 cells and this neurotrophic effect was inhibited partially by anti-NGF blocking antibody in KYSE30 cells, but not in KYSE70 cells. Together, these data indicate that esophageal cancer cells have the ability to stimulate axonogenesis through the production and release of NGF, however, other neurotrophic factors also may be involved.

\section{Discussion}

Emerging evidence in several human cancers has shown that nerves in the tumor microenvironment stimulate cancer progression. ${ }^{9,31}$ A crosstalk exists wherein nerves liberate 

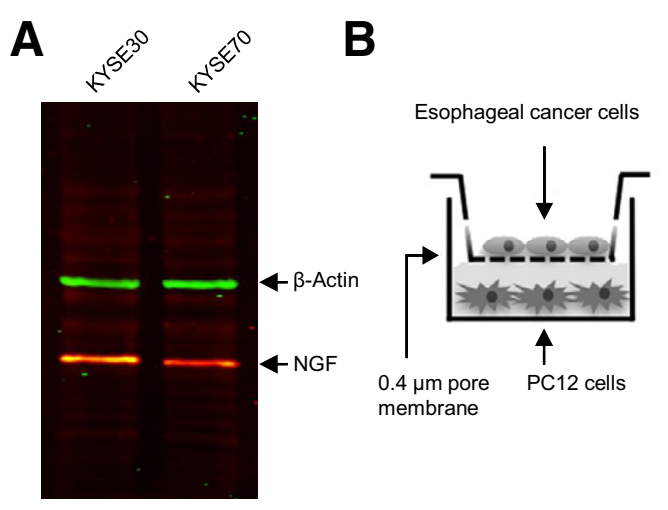

D
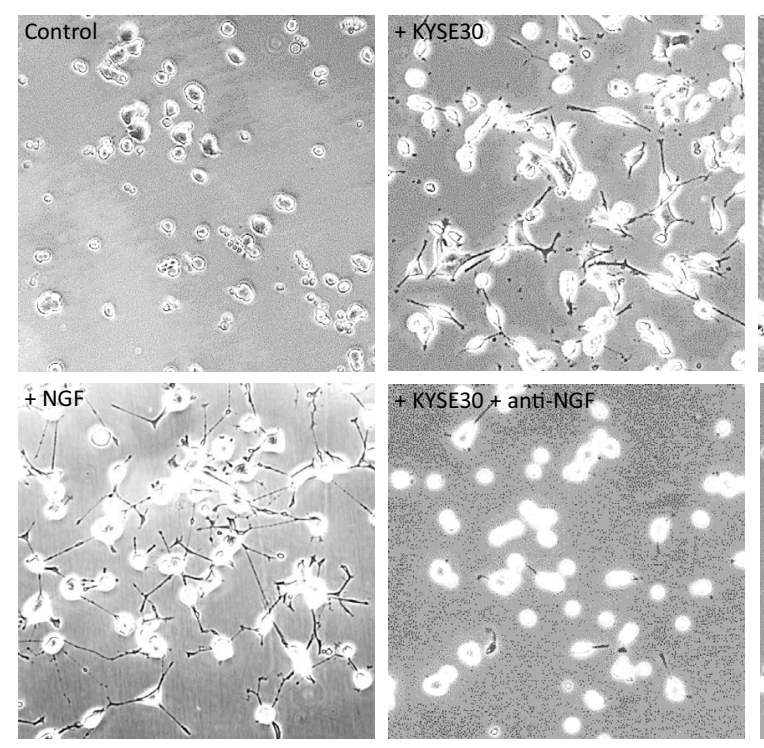
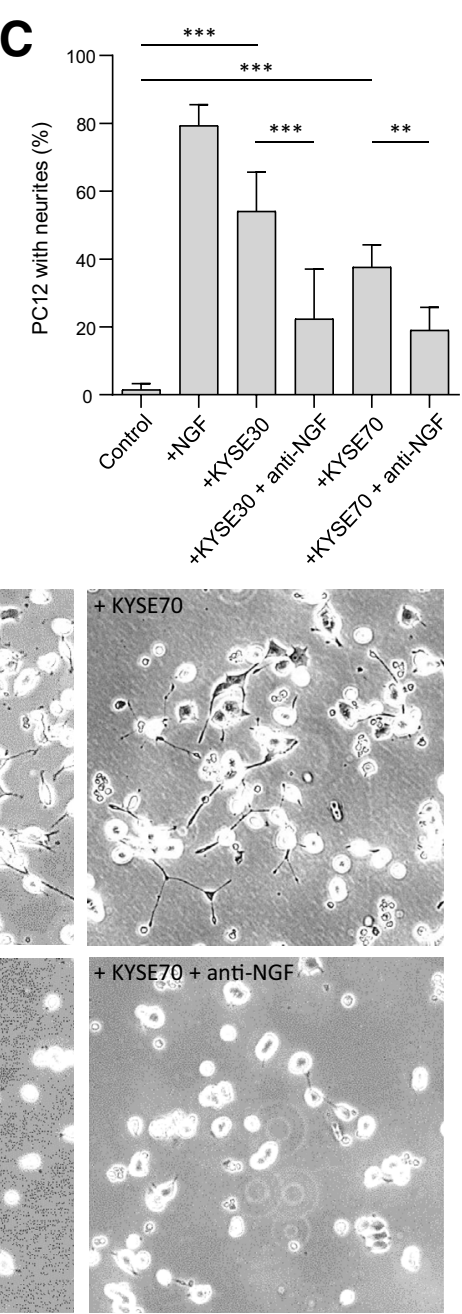

Figure 5 Nerve growth factor (NGF) mediates the neurotrophic effect of esophageal cancer cells. A: Western blot analysis of NGF in esophageal cancer cell lines. NGF is detected at the expected molecular weight. $\beta$-actin was used for normalization. B: Co-culture experiments were performed over 72 hours in transwell Boyden chambers with esophageal cancer cells in the upper compartment and the neuronal PC12 cells in the lower compartment. C: Esophageal cancer cell lines (KYSE30 and KYSE70) are able to induce neurite outgrowth in PC12 cells. Esophageal cancer cells were co-cultured with PC12 cells in the presence or absence of antiNGF blocking antibodies $(1 \mu \mathrm{g} / \mathrm{mL})$. Blocking antibodies against NGF inhibits esophageal cancer cell -induced neurite outgrowth by $32 \%$ in KYSE30 and by $19 \%$ in KYSE70. A negative control (with no esophageal cancer cells) and a positive control (addition of $50 \mathrm{ng} / \mathrm{mL}$ NGF) were performed. The results represent the mean of three independent experiments \pm SD. Quantifications are shown. D: Representative images of the experiment described in panels $\mathbf{B}$ and $\mathbf{C} .{ }^{*} P<0.01,{ }^{* *} P<0.001$. Original magnification, $\times 40$ (D). neurotransmitters to stimulate cancer cell growth and dissemination, while conversely cancer cells release neurotrophic growth factors that attract nerve outgrowth. ${ }^{32}$ However, the presence of nerves in esophageal cancer and their clinicopathologic significance are unclear. The present study suggests that nerve infiltration is a common feature in esophageal cancer that could be driven by NGF released from cancer cells.

The muscular layer of the esophagus is known to be highly innervated. In particular, the act of swallowing is a complex interplay between afferent sensory cranial nerves and inhibitory and excitatory motor neurons of the vagus, which connect muscles of the esophagus to swallowing centers of the brainstem. ${ }^{33,34}$ Therefore, it is not surprising that nearly all $(96 \%)$ normal esophageal tissues in this study were positive for nerves. In normal tissues, nerves almost always were detected in the submucosal and superficial muscularis layer of the esophageal lining. In contrast, nerves were not detected in the mucosal layer of the normal esophagus.

We hereby report that nerves are present within the esophageal tumor microenvironment and are associated particularly with the squamous cell carcinoma histologic subtype. None of the other studied clinicopathologic parameters (age, tumor size, grade, lymph node invasion, and patient survival) were associated with the presence of nerves. Esophageal adenocarcinoma primarily occurs in the lower portion of the esophagus because of its association with Barrett's esophagus, whereas squamous cell carcinomas are found more commonly in the upper and middle portions of the esophagus. ${ }^{35}$ Previous experimental data have shown an increase in sensitivity of the upper esophagus compared with the lower portion, suggesting an increase in innervation to this region. ${ }^{36,37}$ Taken together, it can be hypothesized that the increase in nerve infiltration in squamous cell carcinomas reported here may be associated with the increased innervation of the upper and middle esophagus. Furthermore, the association between upper esophageal tumors and worsening survival ${ }^{38}$ may be related in part to the presence of nerves and their involvement in the microenvironment of squamous cancers.

By performing an analysis of PNI in a large cohort of esophageal tumors, we show that PNI is present and is associated adversely with patient survival. Despite the crucial role of PNI in the dissemination and metastasis of various other human cancers, the mechanisms of PNI and its prognostic 
utility in esophageal cancer still is debated. The reported incidence of PNI in esophageal cancer varies from 5\% to $61 \%$ of cases, however, this variation may be explained by nonstandardized detection methods or definitions of PNI. ${ }^{17}$ The presence of PNI was detected in 12\% of all esophageal cancer cases, representing $31 \%$ of all cases positive for the presence of nerves. The current study data supports the prognostic value of PNI in esophageal cancer and adds to the growing body of evidence suggesting that PNI status should be evaluated systematically in the histopathologic examination of esophageal cancers.

The presence of the neurotrophic receptors NTRK1 and NGFR in nerves within the tumor microenvironment of esophageal cancers was observed frequently in this study, suggesting that these nerves could be stimulated to grow by NGF. Indeed, we report that esophageal cancer cells can activate neuronal outgrowth through NGF release. NGF overexpression reportedly is associated with poor patient outcomes, and an autocrine loop in esophageal cancer cells between NGF and its tyrosine kinase receptor NTRK1 has been described previously. ${ }^{16}$ Interestingly, in pancreatic ${ }^{7}$ and gastric ${ }^{4}$ cancers, NGF release from cancer cells has been shown to be the driver of nerve infiltration in the tumor microenvironment and, similarly, the current study results suggest that NGF may be involved in the innervation of esophageal cancers. However, the correlation between NGF and nerve outgrowth reported in this study was only partial, suggesting that NGF may not be the only factor involved. Various other neurotrophic growth factors are produced throughout the gastrointestinal tract. Brain-derived neurotrophic factor expression is increased in gastric tumors and correlated with poor prognosis. ${ }^{39}$ Glial-derived neurotrophic factor induces neural crest migration and neurite outgrowth in explants of mouse esophagus. ${ }^{40}$ In addition, it is known that artemin, a member of the glial-derived neurotrophic factor family, is expressed in the rat esophagus. ${ }^{41}$ The development of the nervous system involves a variety of neurotrophic molecules and it may be hypothesized that a similar diversity of mechanisms also may participate in esophageal tumor innervation.

In summary, this study shows that esophageal cancers are innervated and suggest that local NGF production by cancer cells drives nerve infiltration into the tumor microenvironment. PNI also was confirmed to be associated with esophageal cancer aggressiveness. This warrants further experimental investigations to define the extent of nerve participation in esophageal cancer growth and determine if the newly established concept of nerve dependence in cancer $^{9}$ also could be relevant in esophageal cancer.

\section{Acknowledgment}

The 50B11 neuronal cells were kindly provided by Dr. Ahmet Höke (John Hopkins University, Baltimore, MD).

\section{Author Contributions}

H.H., P.J., and N.G. designed the study; N.G., F.G., and S.F. performed immunohistochemistry; N.G. performed digital quantification, cell culture experiments, and prepared all figures and tables; M.M.W. (histopathologist) supervised the tissue slide analysis and quantification; C.R. contributed to data analysis, V.W. provided clinical insights; and H.H., S.F., and N.G. drafted the manuscript. The final version of the manuscript was approved by all co-authors.

\section{Supplemental Data}

Supplemental material for this article can be found at http://doi.org/10.1016/j.ajpath.2020.05.012.

\section{References}

1. Faulkner S, Jobling P, March B, Jiang CC, Hondermarck H: Tumor neurobiology and the war of nerves in cancer. Cancer Discov 2019, 9: $702-710$

2. Magnon C, Hall SJ, Lin J, Xue X, Gerber L, Freedland SJ, Frenette PS: Autonomic nerve development contributes to prostate cancer progression. Science 2013, 341:1236361

3. Zhao CM, Hayakawa Y, Kodama Y, Muthupalani S, Westphalen CB, Andersen GT, Flatberg A, Johannessen H, Friedman RA, Renz BW, Sandvik AK, Beisvag V, Tomita H, Hara A, Quante M, Li Z, Gershon MD, Kaneko K, Fox JG, Wang TC, Chen D: Denervation suppresses gastric tumorigenesis. Sci Transl Med 2014, 6:250ra115

4. Hayakawa Y, Sakitani K, Konishi M, Asfaha S, Niikura R, Tomita H, Renz BW, Tailor Y, Macchini M, Middelhoff M, Jiang Z, Tanaka T, Dubeykovskaya ZA, Kim W, Chen X, Urbanska AM, Nagar K, Westphalen CB, Quante M, Lin CS, Gershon MD, Hara A, Zhao CM, Chen D, Worthley DL, Koike K, Wang TC: Nerve growth factor promotes gastric tumorigenesis through aberrant cholinergic signaling. Cancer Cell 2017, 31:21-34

5. Peterson SC, Eberl M, Vagnozzi AN, Belkadi A, Veniaminova NA, Verhaegen ME, Bichakjian CK, Ward NL, Dlugosz AA, Wong SY: Basal cell carcinoma preferentially arises from stem cells within hair follicle and mechanosensory niches. Cell Stem Cell 2015, 16:400-412

6. Saloman JL, Albers KM, Li D, Hartman DJ, Crawford HC, Muha EA, Rhim AD, Davis BM: Ablation of sensory neurons in a genetic model of pancreatic ductal adenocarcinoma slows initiation and progression of cancer. Proc Natl Acad Sci U S A 2016, 113: 3078-3083

7. Renz BW, Takahashi R, Tanaka T, Macchini M, Hayakawa Y, Dantes Z, Maurer HC, Chen X, Jiang Z, Westphalen CB, Ilmer M, Valenti G, Mohanta SK, Habenicht AJR, Middelhoff M, Chu T, Nagar K, Tailor Y, Casadei R, Di Marco M, Kleespies A, Friedman RA, Remotti H, Reichert M, Worthley DL, Neumann J, Werner J, Iuga AC, Olive KP, Wang TC: Beta2 adrenergicneurotrophin feedforward loop promotes pancreatic cancer. Cancer Cell 2018, 33:75-90.e7

8. Kamiya A, Hayama Y, Kato S, Shimomura A, Shimomura T, Irie K, Kaneko R, Yanagawa Y, Kobayashi K, Ochiya T: Genetic manipulation of autonomic nerve fiber innervation and activity and its effect on breast cancer progression. Nat Neurosci 2019, 22:1289-1305

9. Boilly B, Faulkner S, Jobling P, Hondermarck H: Nerve dependence: from regeneration to cancer. Cancer Cell 2017, 31:342-354

10. Zahalka AH, Arnal-Estape A, Maryanovich M, Nakahara F, Cruz CD, Finley LWS, Frenette PS: Adrenergic nerves activate an 
angio-metabolic switch in prostate cancer. Science 2017, 358: $321-326$

11. Pundavela J, Roselli S, Faulkner S, Attia J, Scott RJ, Thorne RF, Forbes JF, Bradshaw RA, Walker MM, Jobling P, Hondermarck H: Nerve fibers infiltrate the tumor microenvironment and are associated with nerve growth factor production and lymph node invasion in breast cancer. Mol Oncol 2015, 9:1626-1635

12. Krarup AL, Olesen SS, Funch-Jensen P, Gregersen H, Drewes AM: Proximal and distal esophageal sensitivity is decreased in patients with Barrett's esophagus. World J Gastroenterol 2011, 17:514-521

13. Thoua NM, Khoo D, Kalantzis C, Emmanuel AV: Acid-related oesophageal sensitivity, not dysmotility, differentiates subgroups of patients with non-erosive reflux disease. Aliment Pharmacol Ther 2008, 27:396-403

14. Woodland P, Aktar R, Mthunzi E, Lee C, Peiris M, Preston SL, Blackshaw LA, Sifrim D: Distinct afferent innervation patterns within the human proximal and distal esophageal mucosa. Am J Physiol Gastrointest Liver Physiol 2015, 308:G525-G531

15. Lu SH, Zhou Y, Que HP, Liu SJ: Peptidergic innervation of human esophageal and cardiac carcinoma. World J Gastroenterol 2003, 9: 399-403

16. Tsunoda S, Okumura T, Ito T, Mori Y, Soma T, Watanabe G, Kaganoi J, Itami A, Sakai Y, Shimada Y: Significance of nerve growth factor overexpression and its autocrine loop in oesophageal squamous cell carcinoma. Br J Cancer 2006, 95:322-330

17. Gao A, Wang L, Li J, Li H, Han Y, Ma X, Sun Y: Prognostic value of perineural invasion in esophageal and esophagogastric junction carcinoma: a meta-analysis. Dis Markers 2016, 2016:7340180

18. Tsai CY, Yeh CJ, Chao YK, Chang HK, Tseng CK, Liu YH: Perineural invasion through the sheath in posttherapy esophagectomy specimens predicts poor survival in patients with esophageal squamous cell carcinoma. Eur J Surg Oncol 2017, 43:1970-1976

19. Xu G, Feng F, Liu Z, Liu S, Zheng G, Xiao S, Cai L, Yang X, Li G, Lian X, Guo M, Sun L, Yang J, Fan D, Lu Q, Zhang H: Prognosis and progression of ESCC patients with perineural invasion. Sci Rep 2017, 7:43828

20. Chen JW, Xie JD, Ling YH, Li P, Yan SM, Xi SY, Luo RZ, Yun JP, Xie D, Cai MY: The prognostic effect of perineural invasion in esophageal squamous cell carcinoma. BMC Cancer 2014, 14:313

21. Lubig $S$, Thiesler $T$, Muller $S$, Vorreuther $R$, Leipner $N$, Kristiansen G: Quantitative perineural invasion is a prognostic marker in prostate cancer. Pathology 2018, 50:298-304

22. Schorn S, Demir IE, Haller B, Scheufele F, Reyes CM, Tieftrunk E, Sargut M, Goess R, Friess H, Ceyhan GO: The influence of neural invasion on survival and tumor recurrence in pancreatic ductal adenocarcinoma - a systematic review and meta-analysis. Surg Oncol 2017, 26:105-115

23. Deng J, You Q, Gao Y, Yu Q, Zhao P, Zheng Y, Fang W, Xu N, Teng L: Prognostic value of perineural invasion in gastric cancer: a systematic review and meta-analysis. PLoS One 2014, 9:e88907

24. Tachezy M, Tiebel AK, Gebauer F, Kutup A, Tharun L, Pantel K, Izbicki JR, Vashist YK: Prognostic impact of perineural, blood and lymph vessel invasion for esophageal cancer. Histol Histopathol 2014, 29:1467-1475

25. Khan OA, Alexiou C, Soomro I, Duffy JP, Morgan WE, Beggs FD: Pathological determinants of survival in node-negative oesophageal cancer. Br J Surg 2004, 91:1586-1591
26. Nagtegaal ID, Odze RD, Klimstra D, Paradis V, Rugge M, Schirmacher P, Washington KM, Carneiro F, Cree IA; WHO Classification of Tumours Editorial Board: The 2019 WHO classification of tumours of the digestive system. Histopathology 2020, 76: $182-188$

27. Faulkner S, Jobling P, Rowe CW, Rodrigues Oliveira SM, Roselli S, Thorne RF, Oldmeadow C, Attia J, Jiang CC, Zhang XD, Walker MM, Hondermarck H: Neurotrophin receptors TrkA, p75(NTR), and sortilin are increased and targetable in thyroid cancer. Am J Pathol 2018, 188:229-241

28. Liebig C, Ayala G, Wilks JA, Berger DH, Albo D: Perineural invasion in cancer: a review of the literature. Cancer 2009, 115: 3379-3391

29. Suter DM, Miller KE: The emerging role of forces in axonal elongation. Prog Neurobiol 2011, 94:91-101

30. Bhattacherjee A, Liao Z, Smith PG: Trophic factor and hormonal regulation of neurite outgrowth in sensory neuron-like 50B11 cells. Neurosci Lett 2014, 558:120-125

31. Jobling P, Pundavela J, Oliveira SM, Roselli S, Walker MM, Hondermarck H: Nerve-cancer cell cross-talk: a novel promoter of tumor progression. Cancer Res 2015, 75:1777-1781

32. Griffin N, Faulkner S, Jobling P, Hondermarck H: Targeting neurotrophin signaling in cancer: the renaissance. Pharmacol Res 2018, 135:12-17

33. Sasegbon A, Hamdy S: The anatomy and physiology of normal and abnormal swallowing in oropharyngeal dysphagia. Neurogastroenterol Motil 2017, 29

34. Goyal RK, Chaudhury A: Physiology of normal esophageal motility. J Clin Gastroenterol 2008, 42:610-619

35. Rice TW, Lerut TE, Orringer MB, Chen LQ, Hofstetter WL, Smithers BM, et al: Worldwide Esophageal Cancer Collaboration: neoadjuvant pathologic staging data. Dis Esophagus 2016, 29: 715-723

36. Woodland P, Sifrim D, Krarup AL, Brock C, Frokjaer JB, Lottrup C, Drewes AM, Swanstrom LL, Farmer AD: The neurophysiology of the esophagus. Ann N Y Acad Sci 2013, 1300:53-70

37. Cicala M, Emerenziani S, Caviglia R, Guarino MP, Vavassori P, Ribolsi M, Carotti S, Petitti T, Pallone F: Intra-oesophageal distribution and perception of acid reflux in patients with non-erosive gastro-oesophageal reflux disease. Aliment Pharmacol Ther 2003, $18: 605-613$

38. Rice TW, Rusch VW, Apperson-Hansen C, Allen MS, Chen LQ, Hunter JG, Kesler KA, Law S, Lerut TE, Reed CE, Salo JA, Scott WJ, Swisher SG, Watson TJ, Blackstone EH: Worldwide Esophageal Cancer Collaboration. Dis Esophagus 2009, 22:1-8

39. Okugawa Y, Tanaka K, Inoue Y, Kawamura M, Kawamoto A, Hiro J, Saigusa S, Toiyama Y, Ohi M, Uchida K, Mohri Y, Kusunoki M: Brain-derived neurotrophic factor/tropomyosin-related kinase B pathway in gastric cancer. Br J Cancer 2013, 108:121-130

40. Yan H, Bergner AJ, Enomoto H, Milbrandt J, Newgreen DF, Young HM: Neural cells in the esophagus respond to glial cell linederived neurotrophic factor and neurturin, and are RET-dependent. Dev Biol 2004, 272:118-133

41. Enomoto H, Crawford PA, Gorodinsky A, Heuckeroth RO, Johnson EM Jr, Milbrandt J: RET signaling is essential for migration, axonal growth and axon guidance of developing sympathetic neurons. Development 2001, 128:3963-3974 